\title{
NOTES ON GLUPHISIA AND OTHER NOTODONTIDAE.-I.
}

\author{
BY A. S. PACKARD, PROVIDENCE, R. I.
}

This paper is mainly based on examinations of the types of the late Henry Edwards, now preserved in the American Museum of Natural History; and for facilities and courtesies I am indebted to the curator of entomology, Mr. W. Beutenmüller.

I regard Gluphisia as the simplest and most primitive genus of the group; its larva being noctuiform and without any projections. The larvae are often, perhaps usually, even, without any red spots. G. trilineata Pack. is the typical species.

G. RIDENDA Edw. is very closely allied, representing $G$. trilineata in Colorado. The Edwards' collection contains three $\delta$. I have a $\$$ from Colorado which I compared with $\mathrm{Mr}$. Edwards's type specimen before his death. Its venation is the same as in G. trilineata; its body and wings are paler gray, the broad median band on the fore wings is clearer, and pale tawny yellowish. It is not improbable that $C$. ridenda will ultimately prove to be merely a climatic variety of the eastern trilineata.

G. RAPTA Edw. I 9 , Colorado, I regard as a variety which should be united with $G$. ridenda. 'The single (type) specimen is a $q$, without antennae or abdomen.

It is of the same size and with the same shape of wings as in G. ridenda. Head and prothorax paler than in $G$. ridenda. Fore wings pale gray, as pale as in ridenda and whiter than in trilineata; base of wings pale, with a black longitudinal streak, a little oblique on the costa, and behind is a diffuse black irregular band; the inner line is black, and as in ridenda. The inner black line forming the inner border of the luteous or tawny yellowish median band is very distinct, oblique, not bent outward as in ridenda. The band is much narrower than in ridenda, the outer and inner black lines nearly meeting on the inner edge of the wing. The outer line is not so much bent on the costa. No middle line present. The space beyond the narrow pale line just beyond the outer line is dusky, much as in trilineata, where it is pale in ridenda. Submarginal scalloped line not so near the edge of the wing as in ridenda. Fringe checkered as in ridenda and trilineata. The hind wings are as in ridenda, with no transverse line. Beneath as in $G$. ridenda, but with a broad dusky cloud on the outer fourth of the fore wings, not reaching the edge.

G. Albofascia Edwards. - The $2 \pi$ type specimens are from Utah, and seem to be only a pale form of $G$. ridenda, probably due to its living in a drier, less rainy, more sunny region. It is to be noted that the western varieties named have no longer fore wings than in the eastern trilineata. It seems to be identical with $G$. formosa, but scarcely separable from $G$. ridenda, being, with little doubt, a climatic variety of the latter species. The two $\delta$ marked albofascia resemble $G$. for- 
mosa, only the nearly clear spaces of the latter in albofascia form dark, broad, very distinct bands. There are two dark dusky patches on the hind wings. The examples of $G$. albofascia are more typical of the species (if it be regarded as distinct from ridenda) than those placed under $G$. formosa.

The fore wings somewhat luteous-gray at base; on the inner third is a broad black band widening on the costa, and still wider on the internal edge, where it reaches a little beyond the middle of the wing. A clear luteous gray median space, beyond which on the outer third of the wing is a broad black band, between which and the submarginal scalloped line is a gray band. Hind wings with a diffuse broad band on the outer fourth, forming a dark patch on the internal angle, and another in the independent interspace. On the under side of the wings the dark bands show through, as do the two dusky spots on the hind wings.

G. FORmosA Edwards. $-4 \delta$, all from Utah. As already stated I regard this as a synonym of $G$. albofascia, both species being with little doubt climatic varieties of $G$. ridenda.

The antennae are well pectinated, rather more so than in G. ridenda. The wings are much paler gray than in ridenda, the hind wings being almost white, but the thorax and abdomen are as in ridenda. Fore wings with black scales at the base, but with no definite lines such as are to be seen in trilineata and ridenda, but just beyond the base the wing is more or less luteous, as in ridenda. Middle of the wing with a broad pale flesh-colored or luteous band, bordered on the inside by a very distinct black line like that of ridenda, becoming wider on the costa. In the middle of the band is a dark line nearly parallel with the inner one, dilat- ing on the veins and all the lines forming distinct dark costal spots. The outer third of the wing gray, with dark scales and with an irregular blackish wavy line, much as in ridenda and rupta. Hind wings whitish, with no lines, and with three dark dots on the fringe of the internal angle. The outer third of the wing faintly dusted more or less with fine dark scales. Wings pale whitish beneath; two blackish costal spots beyond the middle, and costa of both wings speckled with dark scales. A faint diffuse band passes across the hind wings just beyond the middle; and the margin of both wings is speckled with dark scales. Body beneath pale, and the legs (tarsi) ringed with dark scales.

After preparing the preceding descriptions I find that Mr. Edwards adds to his description of $G$. formosa the following remark: "It is possible that $G$. ridenda and G. rupta are forms of one species, and that G. albofascia and $G$. formosa are forms of another, but I prefer to consider them as distinct until future investigation shall determine their true position."

G. LINTNERI (Grote). Originally described as a Dasychira; this is a true Gluphisia, but, with $G$. severa and avimacula, belonging to a distinct section of the genus. The $\delta$ antennae are provided with long close pectinations; the body is stout and hairy; the costa of the fore wings is much more convex than in $G$. trilineata, and the apex somewhat produced as in G. severa.

G. wrighti H. Edwards, Ent. amer. ii, Ir. April, I886. This species inhabits San Bernardino, Cal. It is very near G. severa Edwards (Ent. amer. ii, 167. Dec. I886). 
Of the two female specimens placed under $G$. severa in the Edwards collection, one (not the type, which is a ? from Soda Springs, Cal., April 15, with eggs), probably added after his description was published, I regard as a specimen of $G$. wrightii. Its locality is Sierra Nevada, Cal. (and Mr. Beutenmüller suggests that it may have been taken at Mt. Shasta). The specimen is perfectly preserved, and in its structural character is closely allied to $G$. severa. The thorax has a median tuft as in $G$. severa. From the type of wrightii it differs in the more distinct and darker markings, being less rubbed.

A decidedly luteous subtriangular spot extends from the base of the wing to the inner distinct line crossing the wing, which line is situated half way between the base of the wing and the inner side of the median band, this line having been rubbed off in the type of wrightii. The space between this line and the median band is whitish gray. The broad blackish median band encloses a sinuous linear luteous discal spot, and there is a luteous patch near the internal edge of the wing. The inner edge of the median band is less distinctly sinuous than in the type of wrightii, and so is the white outer bordering line, which, however, is more zigzag. The edge of the wing is stone-gray, as in the type of wrightii, and encloses the usual scalloped dark line, as in the type of wrightii. Hind wings as in the type; a diffuse dark band crosses the wing beyond the middle, and a second outer one is parallel to it, but does not reach the middle, and the two bands enclose a white linear spot, as in the type.

As the species occurs in northern as well as southern California, and is quite variable, severa may have to be united with it.

G. severa Edwards. The single type is a $q$ from Soda Springs, Cal.

The type is much larger than the Sierra Nevada specimen, and well preserved. Antennae with short pectinations. Body and head dark gray. Wings unusually dark; fore wings dark gray on the basal third, with a very small luteous spot on the median and submedian veins. Median band broad and dark, almost black, and not bordered by the narrow scalloped outer line, the wing being suffused with black to the outer edge. A narrow faint luteous linear discal spot. Half way between the scalloped pale gray line and the outer edge of the wing is a submarginal series of tawny or luteous patches. Hind wings just as in the Sierra Nevada example, and venation as in wrightii. Wings underneath dark and much diffused, the line on the fore wing less sinuous than in the wrightii type. Hind wings with two parallel broad dark bands, just as in the Sierra Nevada specimen of G. wrightii. The shape of the head and the wings is the same in the Californian severa and the eastern form. In both forms the hind wings are nearly the same.

I am indebted to Mrs. Annie Trumbull Slosson for the privilege of examining and describing a single remarkable specimen in a perfect state of preservation taken at Franconia, N. H. Mrs. Slosson, unlike many entomologists, has kindly allowed me to partially denude the under side of the wings of her unique specimen, so that the venation could be carefully drawn with the aid of the camera. She has determined the species to be new. The species was not to be found in the collections of $\mathrm{Mr}$. Graef, Mr. Neumogen, and Mr. Beuten- 
müller had not seen it in the Henry Edwards collections, now fortunately in the possession of the American Museum of Natural History at Central Park, New York. I had described the form as Ceruridia slossoniae, regarding it as the type of a new genus, allied to but distinct from Gluphisia, owing to the notable differences in the venation, as well as the presence of a dorsal tuft, and other characters given below. After sending my description for publication Mr. Dyar wrote me that he had seen the specimen with my name on it in $\mathrm{Mrs}$. Slosson's collection, and that it seemed to him to be a dark $\$$ of Gluphisia avimacula Hudson, adding that $\mathrm{Mr}$. Neumogen's "Melia danbyi" is referable to the same genus, but his name "Melia" is preoccupied. Mr. Dyar then rather hastily and with over zeal published my name. Since then I have re-examined Edward's type of G. severa, and have received from Mr. Dyar a specimen of $G$. lintneri. Mr. Dyar also wrote me as his opinion that the species of Ceruridia or Melia (Eumelia) are not generically different from Gluphisia, as he has collected $G$. severa in the Yosemite Valley, Cal.

As the result of my studies, especially of the venation, I am inclined to divide the genus Gluphisia into two sections and to believe that in the forms mentioned below we have a number of climatic or temperature varieties of a species allied to $G$. lintneri (originally referred to Dasychira by Grote), and which is common to both the Atlantic and Pacific coasts. The syn- nonomy may then eventually prove to be somewhat as follows:-

Gluphisia wrighti H. Edwards, Ent. Amer. ii, II. April, I886.

Gluphisia severa H. Edwards, Ent. Amer. ii, I67. Dec. I886.

Melia danbyi Neum. Can. Ent. xxiv, 225, I892.

Eumelia danbyi Neum. Can. Ent. xxv, 25, I 892 .

Gluphisia avimacula Hudson, Ent. News. ii, No. 8, 155. Oct. I891.

Of all these forms the variety slossoniae is the most remarkable, from its very dark markings, and deserves to receive a distinct name. That these forms may be the result of climatic causes, acting on the insect in its pupal state, seems pretty well established from the remarkable results obtained not only by Weismann and W. H. Edwards, but also the more detailed experiments made by Mr. F. Merrifield and published with elaborate plates in the Transactions of the entomological society of London for 1891 (p. 155) and I892, 33, (xxxvi).

In comparing $G$. slossoniae with Hudson's description of avimacula, it seems most probable that it is a melanotic form, due to the colder and damper situation of Franconia, N. H., which is about 1400 feet above the sea. In slossoniae the thorax is lighter, the pale ochreous basal and discal spots of avimacula are whitish gray in slossoniae, and the basal and middle lines of the median band are swamped by the broad black-brown band of slossoniae; the hind wings of slossoniae agree with Hudson's description of avimacula. 

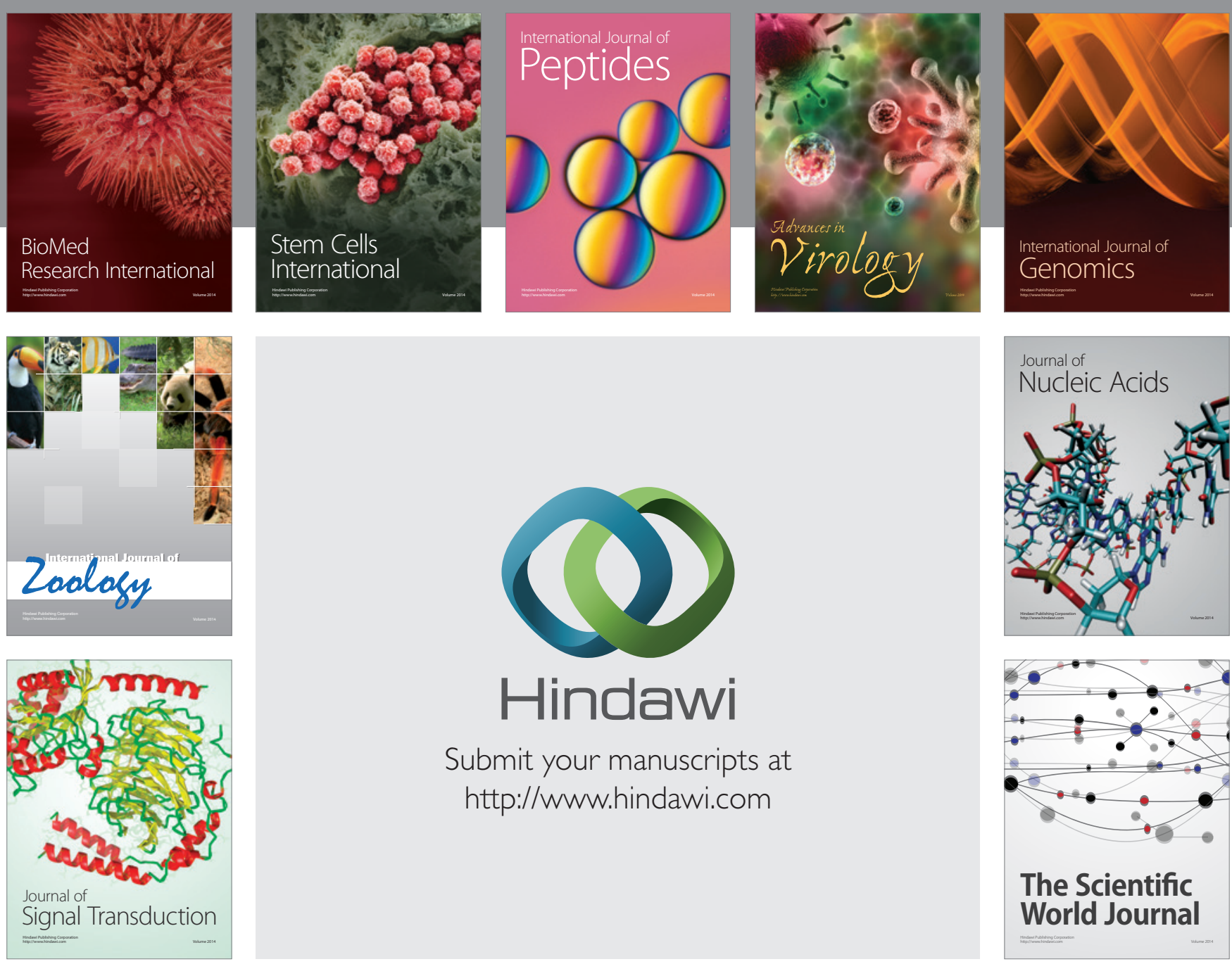

Submit your manuscripts at

http://www.hindawi.com
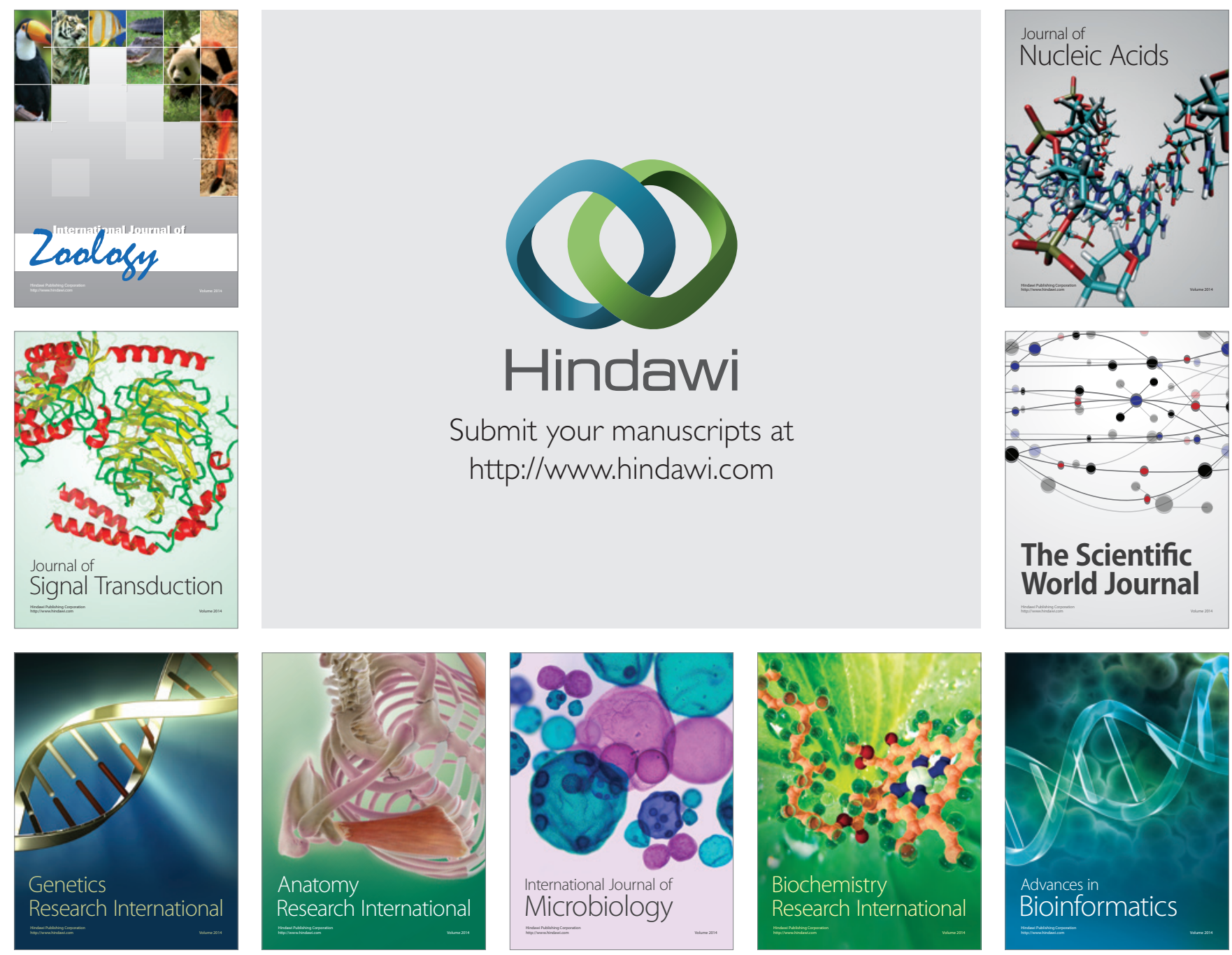

The Scientific World Journal
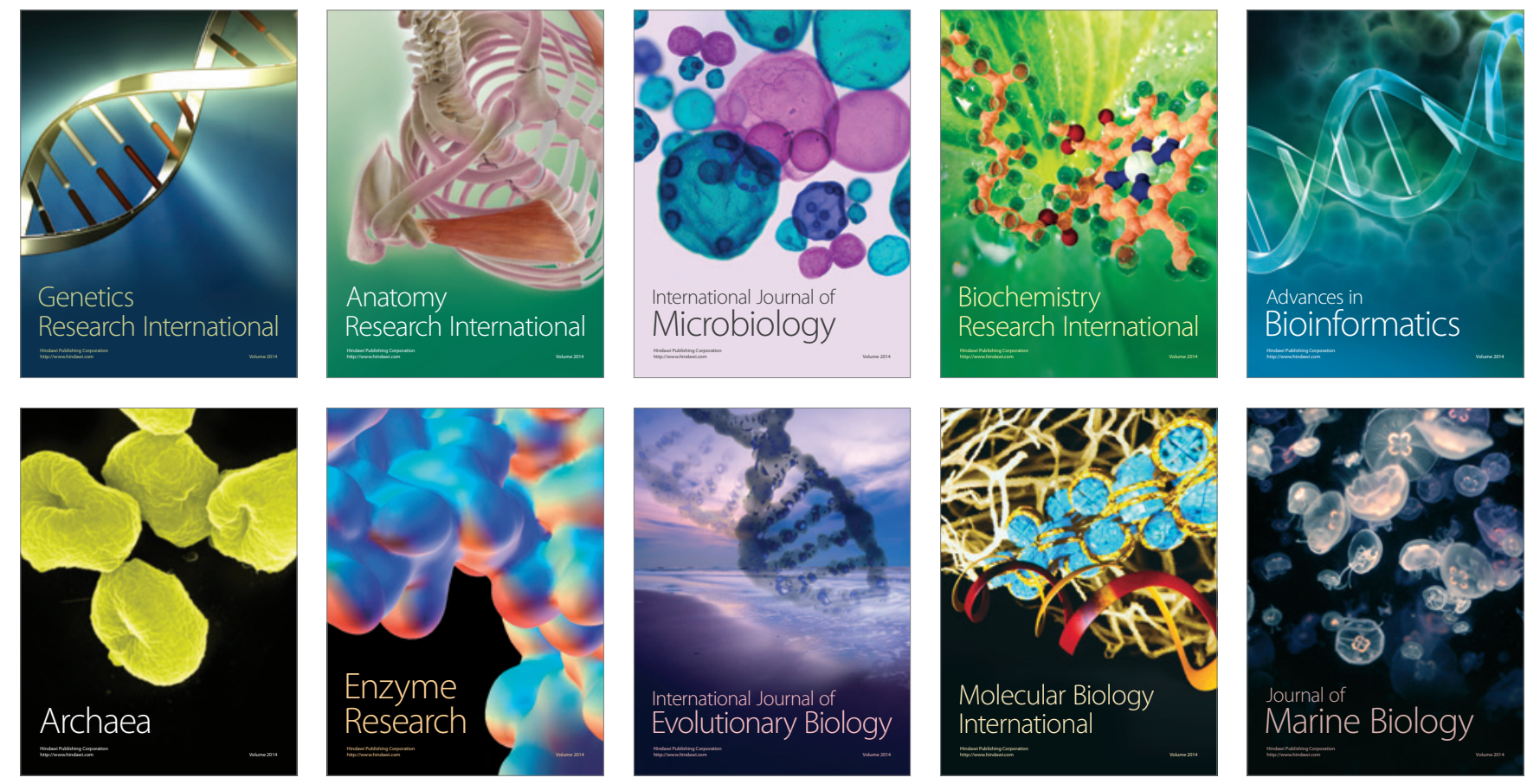